\title{
Long-standing case of osteochondromatosis of the hip treated with uncemented modular bipolar hemiarthroplasty: A case report
}

\section{Eknath D Pawar ${ }^{1}$, Devanshu Gupta ${ }^{1}$, Arohi Sharma ${ }^{1}$, Shashibushan S Varekar ${ }^{1}$, Habung Chobing ${ }^{1}$}

Learning Point of the Article:

Synovial chondromatosis of the hip should be considered as a differential diagnosis and if early treatment options fail, arthroplasty can always be considered as an alternative modality which yields a favorable outcome.

\section{Abstract}

Introduction: Synovial chondromatosis is a rare synovial disorder characterized by the presence of benign loose bodies in the joint space. The affliction of the hip joint is rare. This entity usually goes undiagnosed as it is largely asymptomatic till complications such as secondary osteoarthritis secondary to degenerative changes, subluxation of hip, and fracture neck of femur ensue.

Case Report: A 46-year-old farmer presented with a 9-year long history of the left hip pain with restriction in flexion, extension, and internal rotation. He was diagnosed with synovial chondromatosis and had a history of undergoing arthroscopic debridement following which he was asymptomatic but relapsed after 6 months. We performed excision with uncemented modular bipolar hemiarthroplasty after confirming the diagnosis on plain radiographs and computed tomography. Significant recovery in the range of motion was noted postoperatively and the patient showed no signs of relapse in the follow-up period of 18 months.

Conclusion: Treatment of synovial chondromatosis of the hip joint poses a challenge due to its complex anatomy.

Keywords: Synovial chondromatosis, arthroplasty, hip joint

\section{Introduction}

Primary synovial osteochondromatosis is a benign and rare disorder of the synovium wherein, metaplastic transformation can lead to the formation of intrasynovial loose bodies inside the joint cavity [1]. Over years, the diseased synovia and osteochondral loose bodies can progressively cause damage to the articular surface of cartilage before the disease itself is diagnosed [1]. Treatment options include adequate debridement, removal of loose bodies, and near-total synovectomy performed either through open arthrotomy or arthroscopically. The knee joint is most commonly affected and involvement of hip, shoulder, elbow, and ankle joint is rare. Knee and shoulder joint synovial osteochondromatosis can be adequately treated with arthroscopic surgery. However, surgical management of hip joint synovial osteochondromatosis is much more difficult to treat due to its specific anatomy [1]. If the disorder is not recognized early or left untreated, late complications such as secondary degenerative osteoarthritis, capsular contracture, subluxation of hip, and pathological neck femur fracture can occur which might necessitate other surgical procedures such as hip replacement $[2,3]$.

\section{Case Report}

A 46-year-old man presented with a 9-year history of the left hip pain, limp, and restriction of movements, which was insidious in onset and gradually progressive. The restriction worsened over a period of time. He was a farmer by occupation and since the past 2 years, he could not do his daily routine activities such as squatting, sitting cross-legged, and walk freely beyond $5 \mathrm{~min}$. Furthermore, there was associated with tingling and numbness. There was no history of trauma or any comorbidities. The patient had consulted for the above problems 4 years back and

Author's Photo Gallery

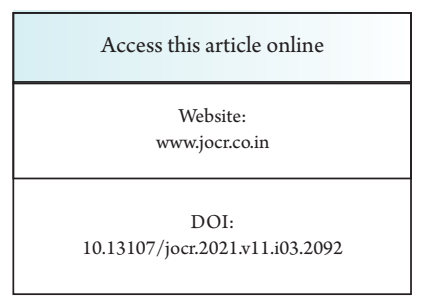

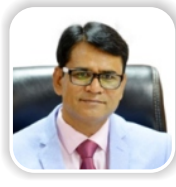

Dr. Eknath D Pawar

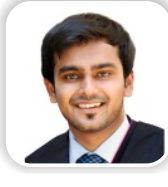

Dr. Devanshu Gupt

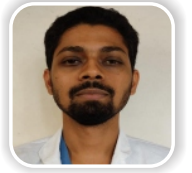

Dr. Arohi Sharm

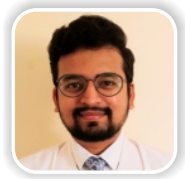

Dr. Shashibushan $S$ Varekar

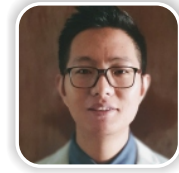

Dr. Habung Chobing
${ }^{1}$ Department of Orthopaedics, Grant Government Medical College and SirJJ Group of Hospitals, Mumbai, Maharashtra, India.

Address of Correspondence:

Dr. Devanshu Gupta,

Department of Orthopaedics, Grant Government Medical College and SirJJ Group of Hospitals, Mumbai, Maharashtra, India. Email:devmittal2293@gmail.com

Journal of Orthopaedic Case Reports | pISSN 2250-0685 | eISSN 2321-3817 | Available on www.jocr.co.in | doi:10.13107/jocr.2021.v11.i03.2092 This is an Open Access article distributed under the terms of the Creative Commons Attribution Non-Commercial License (http://creativecommons.org/licenses/by-nc/3.0) which permits unrestricted non-commercial use, distribution, and reproduction in any medium, provided the original work is properly cited. 


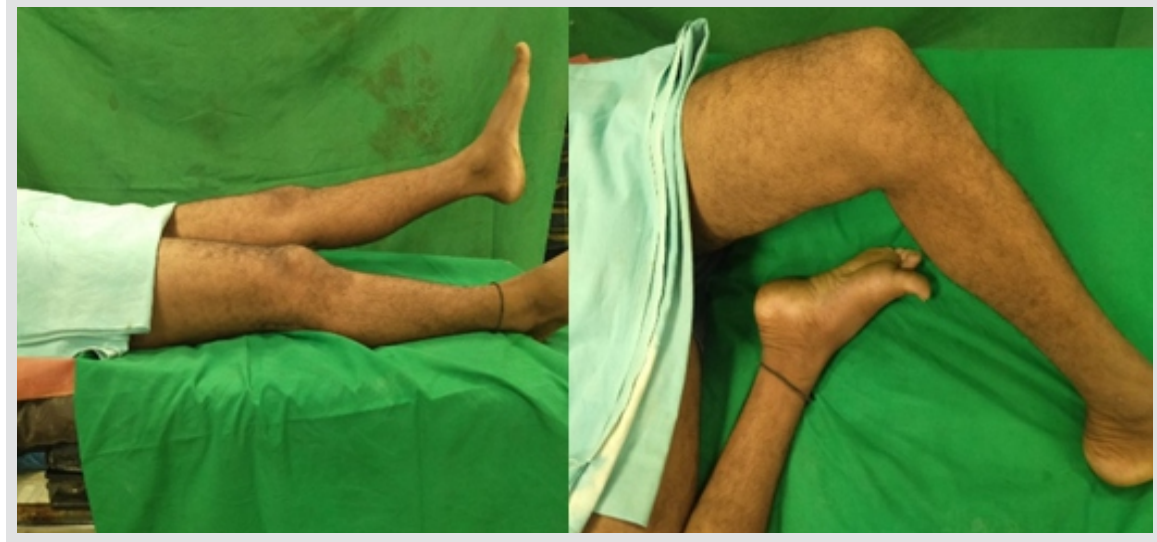

Figure 1: Significant restriction in flexion and internal rotation at the left hip joint at presentation.

was diagnosed with synovial chondramatosis of the hip with early degenerative changes and underwent arthroscopic debridement of hip the details of which were not available. Post the procedure, he had mild symptomatic relief for a brief period but later relapsed and developed the same symptoms. Physical examination revealed tenderness over the left anterior joint line, mild swelling, with severe restriction of flexion, extension, internal and external rotation, and near-normal adduction and abduction at the left hip joint (Fig. 1).

Plain radiographs (Fig. 2) and computed tomography (including three-dimensional reconstruction images) revealed diffuse synovial thickening in the left hip joint. Multiple large conglomerate calcified intra-articular bodies involving the left hip joint with typical ring-and-arc mineralization pattern were visualized (Fig. 3). Degenerative changes involving left femoral head and thinning and erosion of quadrilateral plate of the left acetabulum were present. After discussing the various treatment modalities with the patient, excision biopsy with uncemented modular bipolar hemiarthroplasty was performed under spinal and epidural anesthesia in the lateral position with the posterior approach. Intraoperatively, multiple osteochondral bodies were noted with intra-articular and extra-

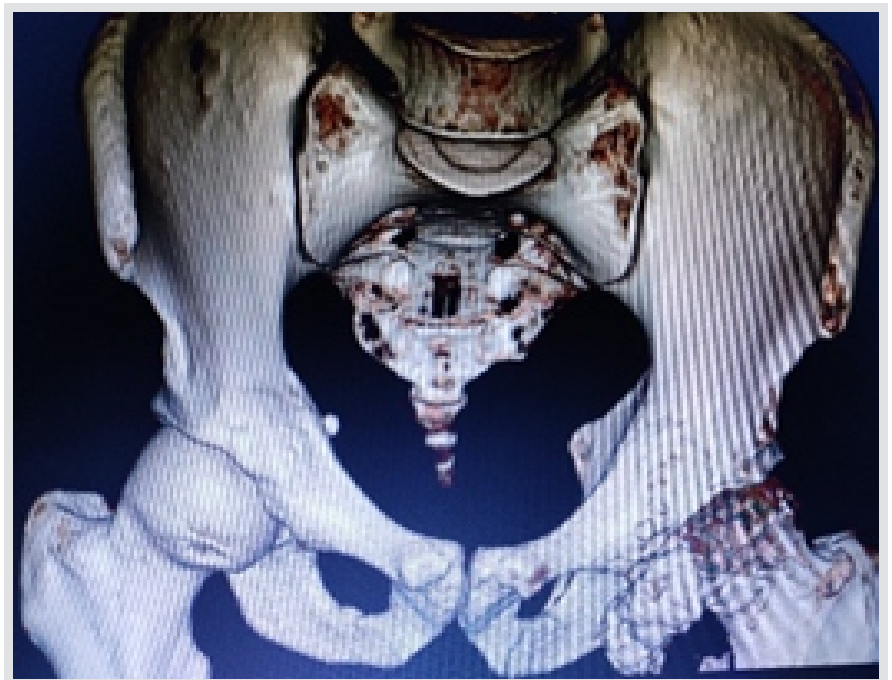

Figure 3: Three-dimensional computed tomography showing degenerative ages in the femoral head with osteochondralloose bodies.

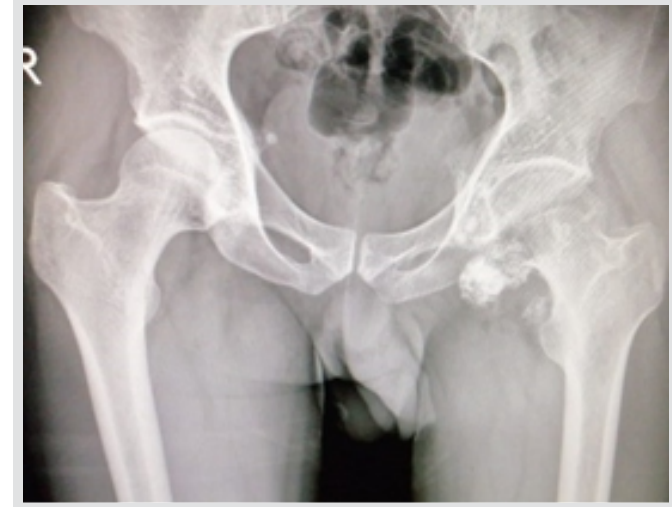

Figure 2: Plain radiograph of the pelvis with both hips showing left hip osteochondral loose bodies with increased sclerosis. articular extensions. Intra-articular bodies along with debris were removed and total synovectomy was performed. Many fragments ranging from 0.1 to $2.5 \mathrm{~cm}$ were removed (Fig. 4). The histopathological examination of the osteochondral bodies and synovial tissue confirmed the presence of cartilaginous synovial metaplasia consistent with synovial chondromatosis (Fig. 5). The loose bodies were composed of cartilage in various stages of calcification and endochondral ossification. Postoperatively, the patient immediately began a hip range of motion exercise followed by weight-bearing walking with a walker. Abductor weakness noted was strengthened with vigorous physiotherapy both passive and active assisted, and by 4 weeks postoperatively, he could return to work. Follow-up was done every 3 months until 18 months (Fig. 6, 7). Significant improvement in the range of motion at the left hip joint was noted (Table 1).

\section{Discussion}

Synovial chondromatosis is a condition characterized by the presence of metaplastic cartilage nodules within the synovium of joints, bursae, or tendon sheath. This condition has been

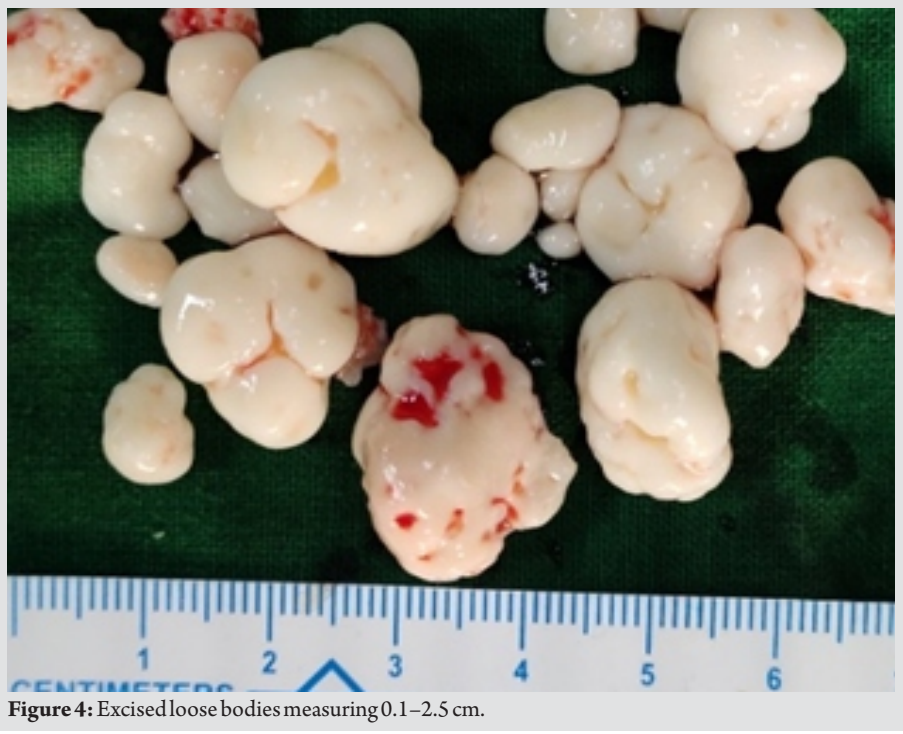

Journal of Orthopaedic Case Reports | Volume 11 | Issue 3 | March 2021 | Page 67-70 


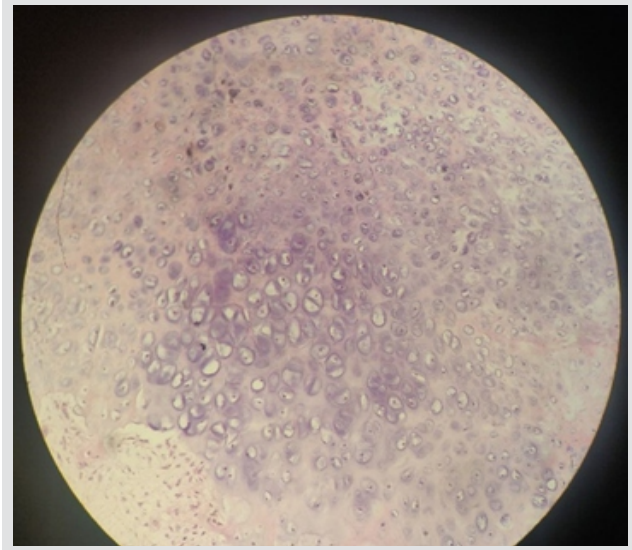

Figure 5: Clusters of chondrocytes showing binucleation on histopathology.

reported predominantly in males between the third and fifth decades [4]. The current etiological hypothesis suggests that it has a neoplastic origin contrary to it being labeled as a reactive process previously [5]. It commonly affects the knee joint and less frequently the pelvis, elbow, wrist, or ankle joint in a monoarticular fashion. Involvement of the hip joint has been noted infrequently [6]. Most cases are asymptomatic with the development of pain, swelling, and stiffness occurring in the later stages. Milgram has described three phases in this disease. The first includes disease activity limited to synovium without loose body formation, the second transitional phase has both intrasynovial lesions and loose bodies. The third is the quiescent phase with no active intrasynovial disease but only loose bodies are present [7].

Mechanical trauma to the joint by the loose bodies can result in secondary osteoarthritis. Other complications include capsular contracture, subluxation of the hip joint, and the pathological neck of femur fracture. Malignant transformation has been reported in up to $5 \%$ cases [8]. All these factors render early diagnosis and treatment vital to minimize subsequent complications. Magnetic resonance imaging remains an important pre-operative investigation to evaluate the exact location and extent of loose bodies, degree of synovial hypertrophy, and extra-articular involvement which helps guide the choice for a surgical approach [9]. Plain radiographs can miss these loose bodies in the absence of ossification or calcification. Therapeutic modalities include removal of the

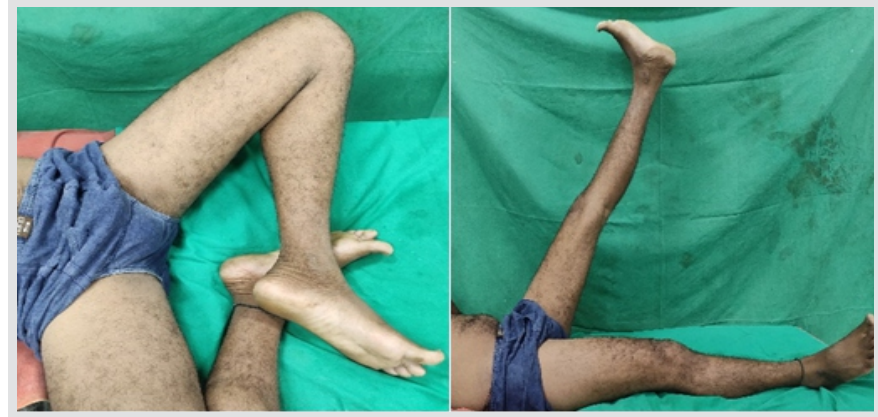

Figure 7: Full range of motion at 18-month postoperatively. cartilaginous loose bodies either using an arthroscopic approach or open debridement with mini-arthrotomy. For cases with secondary osteoarthritis, joint replacement is a feasible option [10]. The arthroscopic approach has benefits including safety and faster post-operative rehabilitation but is associated with higher recurrence rates, ranging between $7 \%$ and $39 \%$ in different studies [11]. In our case, the patient had presented late, with multiple loose bodies, significant intra-articular involvement and secondary degenerative osteoarthritis was present. Pre-operative Harris hip score was found to be $34.3 \%$ which is considered to be poor. The patient opted for uncemented bipolar modular hemiarthroplasty with total synovectomy. The patient had a significant reduction in pain and showed gradual improvement in range of motion aided by physiotherapy. The patient resumed daily activities within 4 weeks and was advised for routine follow-up. At 15 months postoperatively, Harris hip score was $94.3 \%$ which had been persistently excellent over the past 1 year and the patient had good clinical and functional outcomes.

Surgery is necessary for the treatment of synovial chondromatosis. Early diagnosis and management tend to prevent complications related to the joint, wherein arthroscopic debridement and evacuation of loose bodies could be carried out as a safe option. However, if the patient presents late with joint deterioration and the huge number of calcified loose bodies, open debridement with excision of intra-articular loose bodies with hip replacement can be done with good outcome
Table 1: Improvement in the range of motion at the left hip joint.

\begin{tabular}{|c|c|c|c|c|}
\hline $\begin{array}{c}\text { Range of motion } \\
\text { (in degrees) }\end{array}$ & $\begin{array}{c}\text { Normal } \\
\text { range }\end{array}$ & $\begin{array}{c}\text { Pre- } \\
\text { operative }\end{array}$ & $\begin{array}{c}\text { Post- } \\
\text { operative 3 } \\
\text { months }\end{array}$ & $\begin{array}{c}\text { Post- } \\
\text { operative } \\
\text { 18 months }\end{array}$ \\
\hline Flexion & $0-100$ & 30 & 70 & 80 \\
\hline Extension & $0-30$ & 10 & 20 & 30 \\
\hline Internal rotation & $0-30$ & Restricted & 20 & 30 \\
\hline External rotation & $0-45$ & Restricted & 30 & 40 \\
\hline Abduction & $0-45$ & 30 & 30 & 45 \\
\hline Adduction & $0-30$ & 20 & 25 & 30 \\
\hline
\end{tabular}


and minimal risk of recurrence.

\section{Conclusion}

Delay in the diagnosis of synovial chondromatosis of the hip joint is common due to its early asymptomatic phase and late diagnosis can result in complications such as secondary degenerative osteoarthritis, subluxation of hip, and femur neck fracture. The anatomy of the hip joint is complex requiring a long learning curve and expertise for the arthroscopic approach. Thus, arthroplasty remains an effective, easily accessible, and inexpensive modality of treatment with a lower recurrence rate and good clinical outcomes..

\section{Clinical Message}

Here, we present a case of the left hip synovial chondromatosis with degenerative changes managed with modular bipolar uncemented hemiarthroplasty with improvement in range of motion in the post-operative period with no evidence of recurrence over an 18-month follow-up period.

\section{References}

1. Lin CW, Wu CD. Primary synovial osteochondromatosis of the hip joint treated with arthroscopic-assisted mini-open surgery-two case reports. J Orthop Case Rep 2018;8:3841.

2. Ginai AZ. Case report 607: Synovial (osteo) chondromatosis of left hip joint and ileopsoas bursa. Skeletal Radiol 1990;19:227-31.

3. Hardacker J, Mindell ER. Synovial chondromatosis with secondary subluxation of the hip. A case report. J Bone Joint Surg Am 1991;73:1405-7.

4. Shamsunder C, Khalid SA, Sujit Kumar VR. Synovial chondromatosis of the hip Management with synovectomy and partial removal of loose bodies: Case study. Muller J Med Sci Res 2014;5:64-6.

5. Sciot R, Dal Cin P, Bellemans J, Samson I, Van den Berghe H, Van Damme B. Synovial chondromatosis: Clonal chromosome changes provide further evidence for a neoplastic disorder. Virchows Arch 1998;433:189-91.

6. Unni K, Inwards C. Dahlin's Bone Tumours. 6th ed. United States: Lippincott and Williams; 2020. p.36-9.

Conflict of Interest: Nil Source of Support: Nil

Consent: The authors confirm that informed consent was obtained from the patient for publication of this case report

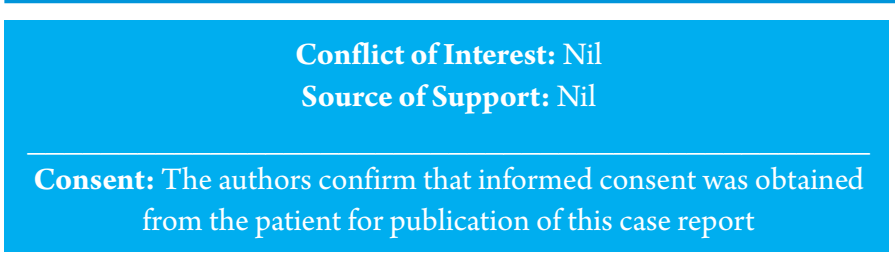

7. Milgram JW. Synovial osteochondromatosis in association with Legg-Calvé-Perthes disease. Clin Orthop Relat Res 1979; 145:179-82.

8. Davis RI, Hamilton A, Biggart JD. Primary synovial chondromatosis: A clinicopathologic review and assessment of malignant potential. Hum Pathol 1998;29:683-8.

9. Zhang YM, Liu X. Surgery of a rare case of multiple synovial osteochondromatosis of the hip joint. J Orthop Case Rep 2016;6:51-4.

10. Prabowo Y, Saleh I, Pitarini A, Junaidi MA. Management of synovial chondromatosis of the hip by open arthrotomy debridement only VS total hip replacement: A case report. Int J Surg Case Rep 2020;74:289-95.

11. de Sa D, Horner NS, MacDonald A, Simunovic N, Ghert MA, Philippon MJ, et al. Arthroscopic surgery for synovial chondromatosis of the hip: A systematic review of rates and predisposing factors for recurrence. Arthroscopy 2014;30:1499-50400.

\section{How to Cite this Article}

Pawar ED, Gupta D, Sharma A, Varekar SS, Chobing H. Long-standing case of osteochondromatosis of the hip treated with uncemented modular bipolar hemiarthroplasty: A case report. Journal of Orthopaedic Case Reports 2021 March;11(3): 67-70. 